\title{
Evaluation of the autochthonous free-floating macrophyte Salvinia biloba Raddi for use in the phytoremediation of water contaminated with lead
}

\author{
Wilfredo Tello Zevallos ${ }^{\mathrm{a}}$, Lucas Matías Salvatierra ${ }^{\mathrm{a}, \mathrm{b}}$, Dana Belén Loureiro ${ }^{\mathrm{a}, \mathrm{d}}$, Jordi Moratóc, \\ Leonardo Martín Pérez ${ }^{a, c, d, *}$ \\ ${ }^{a}$ Facultad de Química e Ingeniería del Rosario, Pontificia Universidad Católica Argentina (UCA-campus Rosario), Av. Pellegrini 3314 \\ (2000) Rosario,Argentina,email: tellowz@gmail.com(W. Tello Zevallos),lucas_salvatierra@uca.edu.ar (L.M. Salvatierra), \\ danaloureiro@uca.edu.ar (D.B.Loureiro),Tel.+54-341-4350214/int.135, email: leonardoperez@uca.edu.ar (L. M. Pérez) \\ ${ }^{b}$ Instituto de Fisicoquimica Teórica y Aplicada (INIFTA, Universidad Nacional de La Plata-Consejo Nacional de Investigaciones \\ Científicas y Técnicas), Diag. 113 y 64 (1900) La Plata, Argentina \\ Cátedra UNESCO de Sostenibilidad, Universidad Politécnica de Catalunya, ESEIAAT-Campus Terrassa, C/Colom 1 (08222) \\ Terrassa (Barcelona), España, email: jordi.morato@upc.edu (J. Morató) \\ ${ }^{d}$ Facultad de Ciencias Bioquímicas y Farmacéuticas, Universidad Nacional de Rosario (UNR) Consejo Nacional de Investigaciones \\ Científicas y Técnicas (CONICET), Suipacha 570 (2000) Rosario, Argentina
}

Received 11 August 2017; Accepted 19 November 2017

\section{A B S T R A C T}

Plant-based systems for the treatment of contaminated environments (phytoremediation) have been proved to be highly efficient in removing pollutants, especially heavy metals. However, in strictly aquatic and high-flow treatment systems, the use of free floating plants could be more adequate. For a treatment system based on phytoremediation strategies to be feasible and sustainable, it is essential that the plants used are not only efficient in pollutants removal, but also abundant in the region, easily accessible, and do not require special culture conditions. In this work, we evaluate the capacity of four different autochthonous macrophytes obtained from the Paraná river (Argentina) to adapt and reproduce without any additional nutrient supply or temperature special conditions (laboratory «indoor» environment). Only those specimens that doubled their biomass in a two-week period without any visual signs of deterioration (loss of turgor, chlorosis and/or necrosis of leaves) were considered for further analysis. From different pre-selected species, only Salvinia biloba Raddi showed a wide capacity to adapt and reproduce under these conditions. Moreover, the ability to remove lead $\left(\mathrm{Pb}^{2+}\right)$ by $S$. bilobawas evaluated in water samples contaminated with three metal concentrations $(4.8 \pm 0.3,9.1 \pm 0.4$ and $19.6 \pm 0.5 \mathrm{mg} / \mathrm{L})$ at different exposure times $(0-24 \mathrm{~h})$, showing a high efficiency in the pollutant elimination. A compartmentalization analysis indicates that surface adsorption was the predominant mechanism for $\mathrm{Pb}^{2+}$ removal at the first $24 \mathrm{~h}$. Finally, the bioconcentration factor (BCF) was calculated at the end of the exposure time,reflecting both hyperaccumulation capacity and high metal tolerance by this plant. Our results suggest that incorporation of S. biloba in wastewater treatment systems could be a successful strategy to efficiently remove heavy metals by bioremediation processes.

Keywords: Heavy metals; Industrial wastewater; Lead; Phytoremediation; Salvinia biloba Raddi

\section{Introduction}

In the last decades, contamination of natural waters by the release of large volumes of aqueous effluents containing

${ }^{*}$ Corresponding author. heavy metals has been increased related to anthropogenic activity and industrialization. Heavy metals are a serious threat to the environment and to human health since these ions are inert to chemical or biological degradation, highly toxic at very low concentrations, and can be transferred

Presented at the International Conference on Water and Sustainability, 26-27 June 2017, Barcelona, Spain

1944-3994 / 1944-3986 @ 2018 Desalination Publications. All rights reserved. 
through the trophic chain posing a serious risk to living beings [1].

Lead $(\mathrm{Pb})$ is omnipresent and one of the earliest metals discovered by the human race. Its unique properties (high malleability, low melting point, resistance to corrosion, among others) have led to its widespread use for different industrial applications, triggering the unfortunate consequence of free lead occurrence in the environment [2]. Lead is present in the wastewaters of petrochemical, painting and coating, founding, metal electroplating, mining, plumbing and battery industries. In most cases, lead is discharged into the environment without any adequate treatment [3]. Lead poisoning has been recognized as a major public health risk, particularly in developing countries. Exposure to lead produces several deleterious effects on the hematopoietic, renal, reproductive, and central nervous system, inducing neurotoxic effects at blood concentrations as low as $20 \mu \mathrm{g} / \mathrm{dL}$ [4]. Although lead toxicity is a highly-explored topic, complete control and prevention over lead exposure is still far from being achieved. While various occupational and public health measures have been undertaken in order to control lead exposure, cases of lead poisoning are still reported [2].

Conventional technologies for the treatment of industrial residual waters containing heavy metals are usually expensive and inefficient because current legislation demands very low metal concentrations as maximum permissible levels [5]. The use of aquatic phytoremediation for the removal of pollutants from wastewater and industrial effluents is a sustainable and promising alternative rather than classical physicochemical procedures [6]. This eco-friendly technology is based on the plant ability to adsorb, accumulate, and tolerate high concentrations of pollutants, including heavy metals [5,7]. Phytoremediation-based technologies have been shown to be competitive compared to more conventional methods, especially for the removal of low metal concentrations wherein toxic effects to plants are minimal or absent. One of its major advantages is that plants can be used as low-cost extract pumps to purify contaminated water, thus being an appropriate solution to remediate large areas or to complete decontamination in longer periods of time [8]. Its success depends on the physicochemical properties of the surface of the plants utilized, and some other biological features such as productivity, geographical distribution and tolerance to toxic compounds [9].

Aquatic phytoremediation has been extensively implemented using helophytes (i.e., emergent plants) in constructed wetlands [10]. However, a second approach may utilize aquatic free-floating plants in lagoons. In such sense, several macrophytes have been used for heavy metal remediation from water samples with the additional advantage that plant biomass can be easily harvested and treated for metal recovery before its final disposal [11]. Vascular floating plants are widely distributed in tropical and subtropical regions, thus, the implementation and management of lagoons for treating metal-containing effluent at these regions appears to be a viable solution since environmental conditions favor high plant productivity [12].

In Argentina, the ecosystem surrounding the Paraná river is characterized by an extensive wetland area with abundant and diverse aquatic vegetation. These regional macrophyte species, which have high efficiency in heavy metal uptake, could be used for the removal of ions in artificial systems or as bioindicators. Therefore, the aim of the present work was to assess the potential of several autochthonous free-floating macrophytes obtained from the Paraná river to be used in the phytoremediation of industrial wastewater contaminated with lead.

\section{Materials and methods}

\subsection{Collection and characterization of macrophytes}

Specimens of Hydrocotyle ranunculoides, Eichhornia crassipes, Lemma minor, and Salvinia sp. were collected from a shallow lake at the middle Paraná river $\left(32^{\circ} 52^{\prime} 37^{\prime \prime} \mathrm{S}-\right.$ $\left.60^{\circ} 40^{\prime} 36^{\prime \prime} \mathrm{O}\right)$, with no known pollution load. The collected plants were transported to the laboratory at ambient temperature in plastic recipients containing river water. Only mature plants with uniform size were selected for experimental purposes. Taxonomic classification was carried out by the Instituto de Botánica del Nordeste (IBONE-CONICET, Universidad Nacional del Nordeste, Corrientes, Argentina) based on morphological characteristics. Salvinia sp. specimens were classified as Salvinia biloba Raddi (synonym name Salvinia herzogii de la Sota) according to the criteria established by [13].

\subsection{Plant material cultivation and selection}

All plants collected were cultivated and maintained in greenhouse conditions under natural light to allow acclimation. Temperatures ranged from 24 to $28^{\circ} \mathrm{C}$. Glass aquaria of $10 \mathrm{~L}$ capacity were used. Fresh plants and water from the sampled natural environment were placed in every aquarium. No further nutrients or special requirements were added to the medium. Only those specimens that doubled their biomass in a two-week period without any visual signs of deterioration (loss of turgor, chlorosis and/or necrosis of leaves) were considered for further analysis.

\subsection{Stock solution of $\mathrm{Pb}(\mathrm{II})$}

The stock solution of $\mathrm{Pb}^{2+}(1000 \mathrm{mg} / \mathrm{L})$ was prepared by dissolving analytical grade $\mathrm{Pb}\left(\mathrm{NO}_{3}\right)_{2}$ (Cicarelli, Santa Fe, Argentina) in deionized water and stored at $4^{\circ} \mathrm{C}$. Standard solutions of $\mathrm{Pb}^{2+}$ for calibration purposes $(1.0,5.0,10,15,20$, $25,30 \mathrm{mg} / \mathrm{L})$ were prepared as recommended for Varian AA240FS operational manual, by diluting the stock solution with the necessary volume of deionized water in glass calibrated containers. All calibration procedures showed reproducible linear relationships $\left(R^{2}=0.995\right)$.

\subsection{Batch kinetic studies}

The plants selected as the best adapted to growth in un-supplemented conditions were rinsed gently with deionized water and placed in rectangular glass containers $(20 \mathrm{~cm} \times 35 \mathrm{~cm})$ with different initial concentrations of $\mathrm{Pb}^{2+}(4.8 \pm 0.3,9.1 \pm 0.4$ and $19.6 \pm 0.5 \mathrm{mg} / \mathrm{L})$ in 1.5 $\mathrm{L}$ final volume. The metal concentrations selected were 
in accordance with previously reported data $[3,14,20]$. The experiments were accomplished at an average room temperature of $23 \pm 2^{\circ} \mathrm{C}$ in the presence of fluorescent tubes (OSRAM DULUX L HE, Germany) light intensity $(100 \mathrm{~lm} / \mathrm{W})$ for a photo period of $12 \mathrm{~h}$. The batch kinetic study was conducted with $20.0 \mathrm{~g}$ of fresh plant in each recipient. The fresh weight of plant biomass was determined after removing the excess of liquid over a filter paper. Eight experimental units were used as replicates for each exposure time $(0.5,2,4,6,12$ and $24 \mathrm{~h})$ and the data were reported as mean value \pm standard deviation (S.D.). Additionally, two controls were carried out. One, containing $\mathrm{Pb}^{2+}$ at the same initial concentration of the treatment without biomass, was used to determine the possible adsorption of the metal onto the surface of the containers. The content of lead in the water column did not change along the experimental time, indicating that no lead adsorption occurred in the system. Another control, containing biomass in water without $\mathrm{Pb}^{2+}$, was used as blank of the experiment in which no lead was quantified either in plant or medium.

In all cases, $\mathrm{pH}$ was adjusted and maintained at $6.0 \pm$ 0.5 with $1 \mathrm{~N} \mathrm{HNO}_{3}$ (Cicarelli, Santa Fe, Argentina) in order to avoid $\mathrm{Pb}(\mathrm{OH})_{2}$ precipitation. Water samples were withdrawn after the consecutive hours of contact period and residual concentration of $\mathrm{Pb}^{2+}$ was measured. Total biomass was removed and treated for compartmentalization analysis after each exposure time.

\subsection{Lead adsorption kinetics and lead adsorption equilibrium}

First and second order models were applied to evaluate the kinetics of $\mathrm{Pb}^{2+}$ elimination from water samples. The linear form of the first (1) and second (2) order rate equations are expressed as follows:

$\ln C_{t}=\ln C_{0}-K_{1} C_{t}$

$\frac{1}{C_{t}}-\frac{1}{C_{0}}=k_{2} t$

where $C_{t}=$ residual concentration of $\mathrm{Pb}^{2+}(\mathrm{mg} / \mathrm{L})$ at time $t$, $\mathrm{C}_{0}=$ initial $\mathrm{Pb}^{2+}$ concentration $(\mathrm{mg} / \mathrm{L}), K_{1}=$ first order reaction rate constant, $K_{2}=$ second order reaction rate constant.

Pseudo-first order or Lagergren model [15] and pseudo-second order [16] rate equations were used for evaluating the kinetics of $\mathrm{Pb}^{2+}$ adsorption to $S$. biloba biomass. The linearized form of the pseudo-first order kinetic model proposed by Lagergren [15] is:

$\ln \left(q_{e}-q_{t}\right)=\ln q_{e}-k_{1} t$

where $q_{e}=$ amount of solute adsorbed per unit weight of adsorbent at equilibrium, $q_{t}=$ amount of solute adsorbed per unit weight of adsorbent at time $t, k_{1}=$ pseudo-first order reaction rate constant.

The linear form of the pseudo-second order equation proposed by Ho and Mckay [16] is:

$\frac{t}{q_{t}}=\frac{1}{k_{2} q_{e}^{2}}+\frac{\mathrm{t}}{q_{e}}$
The above equation is the integrated rate law for a pseudo-second order reaction, which after rearrangement is expressed in the following form:

$\frac{t}{q_{t}}=\frac{1}{h}+\frac{1}{q_{e}} t$

where $h=k_{2} q_{e}^{2}\left(k_{2}=\right.$ pseudo-second order reaction rate constant), $q_{e}=$ amount of solute adsorbed per unit weight of adsorbent at equilibrium, and $q_{t}=$ amount of solute adsorbed per unit weight of adsorbent at time $t$.

The Langmuir and the Freundlich isotherm models were chosen to describe the adsorption equilibrium of $\mathrm{Pb}^{2+}$ [3]. The Langmuir adsorption model can be derived from Eq. (6):

$q=\frac{q_{\max } b C_{e}}{1+b C_{e}}$

where $q$ is the mass of sorbate adsorbed per unit mass of sorbent $(\mathrm{mg} / \mathrm{g}), b$ is the Langmuir constant, $C_{e}$ is the equilibrium concentration $(\mathrm{mg} / \mathrm{L})$, and $q_{\max }$ is the adsorption capacity $(\mathrm{mg} / \mathrm{g})$.

The Freundlich adsorption isotherm is mathematically expressed as Eq. (7):

$q=K_{F} C_{e}^{1 / n}$

Once again, $q$ is the adsorption capacity $(\mathrm{mg} / \mathrm{g}), C_{e}$ is the equilibrium concentration $(\mathrm{mg} / \mathrm{L}), 1 / n$ is the sorption intensity, and $K_{F}$ is the measure of sorption capacity.

\subsection{FTIR-ATR analysis}

The spectra of dry S. biloba biomass were obtained using a Fourier Transform Infrared (FTIR) spectrophotometer Shimadzu IR Prestige-21 (Tokyo, Japan) with Attenuated Total Reflectance (ATR) attachment. Measurements were recorded in the scanning range of $500-4000 \mathrm{~cm}^{-1}$. A total of 20 scans were performed at $2 \mathrm{~cm}^{-1}$ resolution.

\subsection{Compartmentalization analysis}

To assess the distribution of $\mathrm{Pb}^{2+}$ among compartments (remainder in the water column, adsorbed on the plant surface and accumulated in the plant tissue), an analysis of compartmentalization was carried out as described by [14]. Samples from the water column were collected at the end of each exposure time in the batch kinetic experiments and filtered using Whatman paper (pore size $=11 \mu \mathrm{m}$ ). Biomass was collected and washed with deionized water to remove residues from the medium. After removing the excess of liquid over a filter paper, plant biomass was washed with 400 $\mathrm{mL}$ of $1.7 \mathrm{mM}$ EDTA solution (concentration equivalent to a molar ratio EDTA/ $\mathrm{Pb}^{2+} \geq 15$ ) for $60 \mathrm{~min}$ in an orbital shaker at $180 \mathrm{rpm}$. Samples from this washing were taken to quantify $\mathrm{Pb}^{2+}$ adsorbed on the plant surface. The EDTA-washed biomass was then rinsed with deionized water and dried at $90^{\circ} \mathrm{C}$ to constant weight. Samples of $0.05 \mathrm{~g}$ of this dried-bio-

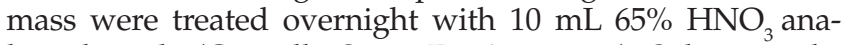
lytical grade (Cicarelli, Santa Fe, Argentina). Subsequently, samples were heated at $120^{\circ} \mathrm{C}$ in a digestion system for $2 \mathrm{~h}$. 
Aliquots of those samples were diluted with deionized water to quantify $\mathrm{Pb}^{2+}$ accumulated into the plant tissue. All the samples were analyzed in an atomic absorption spectrophotometer Varian AA240FS (Varian Inc., Palo Alto, CA, EEUU) at $207 \mathrm{~nm}$ using an air-acetylene flame [17].

\subsection{Calculation of the bioconcentration factor}

The bioconcentration factor (BCF) was calculated as an indicator of plant lead removal efficiency according to [18] as follows:

$$
\mathrm{BCF}=\frac{\mathrm{Pb}^{2+} \text { in total biomass }(\mathrm{mg} / \mathrm{Kg} \text { dry biomass })}{\mathrm{Pb}^{2+} \text { initial concentration in solution }(\mathrm{mg} / \mathrm{L})}
$$

\subsection{Statistical analysis}

Linear regression, non-linear regression and variance analyses (ANOVA) were carried out using the SigmaStat 3.5 software (Systat Software Inc., San Jose, CA, USA) at $p$ $=0.05$ level.

\section{Results and discussion}

\subsection{Plants selection for metal remediation studies}

In order for an aquatic system based on phytoremediation strategies to be feasible for contaminants elimination, it is essential that the macrophytes used in the system design do not require special culture conditions. Properties such as high biomass productivity and high sorption capacity are essential features when applying these technologies. In this study, from the different autochthonous aquatic macrophytes collected from Paraná river that were analyzed, only $S$. biloba showed a remarkable capacity to grow and reproduce under greenhouse conditions. Among various species, Salvinia holds a distinctive position due to several advantages including high yield and tolerance to a wide range of temperatures. It is widely spread in tropical zones but it is also found in subtropical and temperate zones. In Argentina, it grows abundantly in wetlands. Specimens from this genus can be easily and inexpensively handled. The capability of Salvinia for mass-scale use in phytoremediation must be highlighted since different species, including S. minima, S. auriculata, S. natans, and S. rotundifolia, have demonstrated high potential to remove heavy metals from wastewaters [19]. Based on this background and our observations, the free-floating aquatic plant $S$. biloba was selected for further experiences.

\subsection{Batch sorption kinetics}

In order to establish the capacity of S. biloba to remove $\mathrm{Pb}^{2+}$, a series of batch experiments were carried out using deionized water as the experimental medium and three different metal concentrations $(4.8 \pm 0.3,9.1 \pm 0.4$ and $19.6 \pm$ $0.5 \mathrm{mg} / \mathrm{L}$ ). In all cases, $\mathrm{Pb}^{2+}$ in water decreased over time and most of this reduction took place during the first $24 \mathrm{~h}$ (Fig. 1). As can be seen in Table 1, metal elimination by $S$. biloba reached more than $95 \%$ removal at $24 \mathrm{~h}$ for $4.8 \pm 0.3$

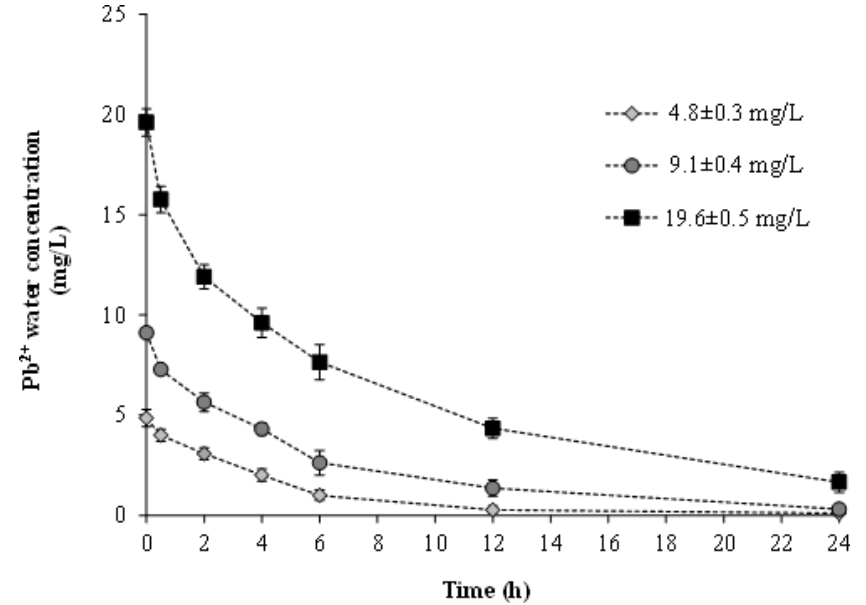

Fig. 1. Lead $\left(\mathrm{Pb}^{2+}\right)$ removal kinetics from water column by S. biloba.

Table 1

Percentage of removed $\mathrm{Pb}^{2+}$ at different exposure times for various metal initial concentrations

\begin{tabular}{llll}
\hline Time $(\mathrm{h})$ & \multicolumn{3}{c}{$\mathrm{Pb}^{2+}$ removal $(\%)$} \\
\cline { 2 - 4 } & $4.8 \pm 0.3 \mathrm{mg} / \mathrm{L}$ & $9.1 \pm 0.4 \mathrm{mg} / \mathrm{L}$ & $19.6 \pm 0.5 \mathrm{mg} / \mathrm{L}$ \\
\hline 0 & 0 & 0 & 0 \\
0.5 & $17.7 \pm 0.3^{\mathrm{a}}$ & $20.1 \pm 1.4^{\mathrm{a}}$ & $19.7 \pm 4.0^{\mathrm{a}}$ \\
2 & $36.8 \pm 1.4^{\mathrm{b}}$ & $38.3 \pm 6.1^{\mathrm{b}}$ & $39.4 \pm 4.0^{\mathrm{b}}$ \\
4 & $58.8 \pm 3.7^{\mathrm{c}}$ & $52.7 \pm 0.3^{\mathrm{b}}$ & $51.1 \pm 5.5^{\mathrm{bc}}$ \\
6 & $80.0 \pm 10.5^{\mathrm{d}}$ & $71.7 \pm 10.7^{\mathrm{c}}$ & $61.1 \pm 7.0^{\mathrm{cd}}$ \\
12 & $94.5 \pm 3.3^{\mathrm{de}}$ & $84.9 \pm 4.6^{\mathrm{cd}}$ & $77.9 \pm 3.4^{\mathrm{d}}$ \\
24 & $97.7 \pm 0.1^{\mathrm{e}}$ & $96.6 \pm 0.4^{\mathrm{d}}$ & $91.6 \pm 2.1^{\mathrm{e}}$ \\
\hline
\end{tabular}

Results are presented as mean \pm S.D. Different letters in the same column represent significant statistical difference $(p<$ $0.05)$; e.g., "a" and " $\mathrm{b}$ " are statistically different from each other but not from "ab".

and $9.1 \pm 0.4 \mathrm{mg} / \mathrm{L}$ of initial $\mathrm{Pb}^{2+}$ concentration, but this percentage slightly declined at $19.6 \pm 0.5 \mathrm{mg} / \mathrm{L}$. After a contact period of 7 days with the highest initial $\mathrm{Pb}^{2+}$ concentration, approximately $98.7 \%$ removal was observed [20]. It is interesting to note that, in all cases, remnant $\mathrm{Pb}^{2+}$ in water samples were below the limit of admissible lead discharge in industrial waste liquids ( $<0.50 \mathrm{ppm})$, established by resolution No. 1089/82 (Santa Fe, Argentina). Throughout all the bioassays, plants general appearance was good and no growth differences or evidence of necrosis was observed.

The elimination of $\mathrm{Pb}^{2+}$ from the water column was around $50 \%$ after $4 \mathrm{~h}$ for each initial metal concentration assayed (Table 1). During the following $8 \mathrm{~h}$, at the two lowest $\mathrm{Pb}^{2+}$ concentrations, the metal was almost fully eliminated from the water column ( $85-95 \%$ of the metal), whereas at the highest $\mathrm{Pb}^{2+}$ concentration, the removal continued until $24 \mathrm{~h}$, when about $90 \%$ metal elimination was reached. In addition, $\mathrm{Pb}^{2+}$ elimination from the water column fits a first order reaction model, indicating that the rate of this process depends of the initial concentration of the metal. That is, 
Table 2

Rate constants of first $\left(K_{1}\right)$ and second $\left(K_{2}\right)$ order kinetic models obtained for $\mathrm{Pb}^{2+}$ elimination from the water column by S. biloba biomass at different metal concentrations

\begin{tabular}{lllll}
\hline $\begin{array}{l}\mathrm{Pb}^{2+} \text { initial } \\
\text { concentration } \\
(\mathrm{mg} / \mathrm{L})\end{array}$ & \multicolumn{2}{l}{ First order kinetics } & \multicolumn{2}{l}{ Second order kinetics } \\
\cline { 2 - 5 } & $\mathrm{K}_{1}(1 / \mathrm{h})$ & $\mathrm{R}^{2}$ & $K_{2}(\mathrm{~L} / \mathrm{mg} \cdot \mathrm{h})$ & $\mathrm{R}^{2}$ \\
\hline $4.8 \pm 0.3$ & 0.163 & 0.9930 & 0.379 & 0.8900 \\
$9.1 \pm 0.4$ & 0.137 & 0.9873 & 0.126 & 0.9077 \\
$19.6 \pm 0.5$ & 0.098 & 0.9751 & 0.022 & 0.9638 \\
\hline
\end{tabular}

as $\mathrm{Pb}^{2+}$ concentration increases, its removal rate ( $K$ value) decreases (Table 2).

The data depicted in Fig. 2 reveal a biphasic nature of $\mathrm{Pb}^{2+}$ uptake with a first rapid sorption process up to a period of $6 \mathrm{~h}$, reaching almost equilibrium after $12 \mathrm{~h}$. These observations suggest that the rate of the sorption process is diffusion controlled by metal concentration differences between the bulk solution and the roots microcosm.

The rapid rate of removal at the earlier period may be explained due to the high availability of active sites at the plant root membranes but, as time increases, removal rate decreases due to the saturation of these sites. Similar patterns have been described by other authors for the removal of numerous metal ions using a wide variety of aquatic macrophytes, including Salvinia species $[3,14,19,21-23]$. Plant cells have an abundance of negatively charged sites on their walls, and hence several interactions between metals and carboxyl, sulphate, amino and other groups are likely to occur [24]. Surface sorption is a combination of physical and chemical processes such as chelation, ion exchange and chemical precipitation of metal ions [25]. Biological processes (intracellular uptake and traslocation to the aerial parts) and root-mediated precipitation of metal (particularly pronounced at high metal concentrations) are probably responsible for the slower components of $S$. biloba lead removal mechanism [21].

Our results demonstrate that metal concentration and exposure time directly affect pollutant removal efficiency. Removal of $\mathrm{Pb}^{2+}$ using $S$. biloba proved to be fast enough to reach a state of equilibrium between the first 12-24 h of exposure at all metal concentrations evaluated. When the aim is to control the operation cycles of an effluent treatment system that utilizes aquatic plants as part of the bioremediation mechanism, it is important to know the time required to reach certain degree of contaminant removal. In this way, it is possible to adapt the periodicity of the discharges that impact the system, establishing a minimum of resting time that allows the system to recover part of its phytoremediation capacity.

The batch kinetic results were also tested in two models in order to evaluate the best fit sorption reaction mechanism: pseudo-first order equation on the basis of adsorbent uptake capacity [15] and pseudo-second order reaction model based on the solid-phase sorption [16]. Kinetic parameters obtained from both proposed models at different metal initial concentrations are presented in Table 3. Metal adsorption by $S$. biloba biomass was satisfactorily adjusted to a pseudo-second order kinetic model for all $\mathrm{Pb}^{2+}$

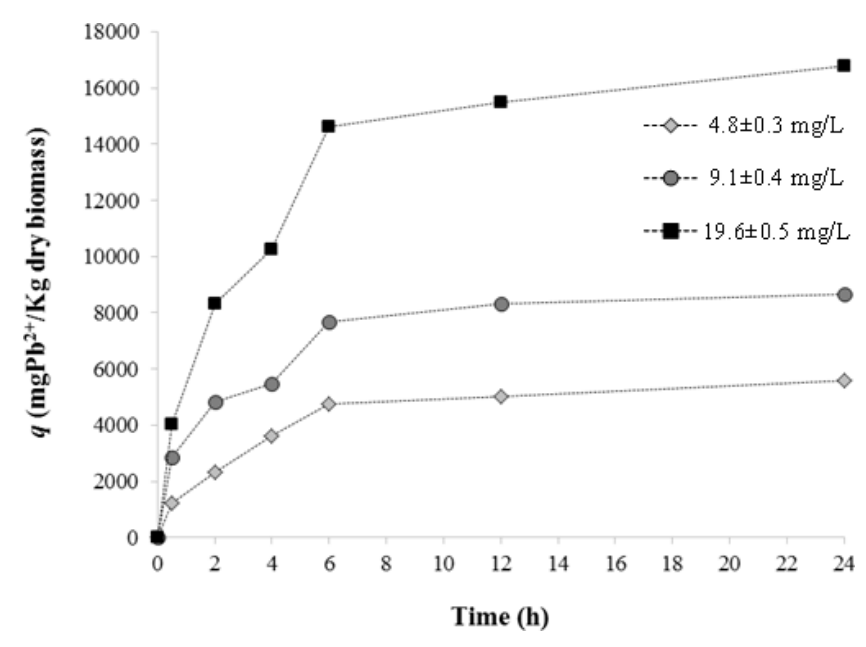

Fig. 2. Lead $\left(\mathrm{Pb}^{2+}\right)$ adsorption kinetics of S. biloba at different initial concentrations.

concentrations tested, with high coefficients of determination (Table 3). The adsorption capacity at equilibrium $\left(q_{e}\right)$ and the initial adsorption rate $(h)$ significantly increased as the metal content in the solution increased. These results indicate that increasing metal concentrations in water samples cause more interactions between the metal and the biomass to occur. In contrast, the pseudo-second order rate constant $\left(k_{2}\right)$ decreased as $\mathrm{Pb}^{2+}$ concentration increased. In this case, when the same amount of bio-adsorbent is used (20.0 $\mathrm{g}$ at this work), active adsorption sites may be more rapidly saturated with increasing pollutant concentration, reducing the speed of the adsorption process. Similar values to those described here for $q_{e^{\prime}} h$ and $k_{2}$ have been previously described by [3] for an analogous batch system operating with S. minima.

Pseudo-second order kinetics model has been extensively used to describe the sorption of divalent metal ions onto highly heterogeneous surfaces [26]. Most adsorption systems follow this model in which chemisorption took place during the adsorption process [27]. Therefore, it is possible to assume that the mechanism of adsorption of $\mathrm{Pb}^{2+}$ by $\mathrm{S}$. biloba involves the formation of strong chemical bonds, mainly by ionic exchange. In fact, several authors have reported that other ions such as $\mathrm{Na}^{+}, \mathrm{K}^{+}, \mathrm{Ca}^{2+}, \mathrm{Mg}^{2+}$, $\mathrm{Fe}^{3+}$ and $\mathrm{Mn}^{2+}$ are liberated into the solution during the adsorption of $\mathrm{Pb}^{2+}, \mathrm{Cd}^{2+}, \mathrm{Zn}^{2+}$, or $\mathrm{Ni}^{2+}$ by different aquatic macrophytes [28-30].

\subsection{Adsorption isotherms}

There are several isotherm equations available for analyzing the behavior of adsorbent materials during the removal of contaminants in wastewater, the Langmuir and Freundlich models being the most common. The Langmuir isotherm model assumes that a finite number of active sites are uniformly distributed over the adsorbent surface. These active sites have the same affinity for adsorption of a mono molecular layer and there is no interaction between adsorbed molecules. In contrast, the Freundlich isotherm model applies to adsorption on heterogeneous surfaces 
Table 3

Parameters of pseudo-first order and pseudo-second order kinetic models obtained for $\mathrm{Pb}^{2+}$ adsorption by S. biloba biomass at different metal concentrations

\begin{tabular}{llllllll}
\hline $\begin{array}{l}\mathrm{Pb}^{2+} \text { initial } \\
\text { concentration }(\mathrm{mg} / \mathrm{L})\end{array}$ & \multicolumn{3}{l}{ Pseudo-first order kinetics } & \multicolumn{5}{l}{ Pseudo-second order kinetics } \\
\cline { 2 - 8 } & $q_{e}(\mathrm{mg} / \mathrm{g})$ & $k_{1}(1 / \mathrm{h})$ & $\mathrm{R}^{2}$ & $q_{e}(\mathrm{mg} / \mathrm{g})$ & $k_{2}(\mathrm{~g} / \mathrm{mg} \cdot \mathrm{h})$ & $h(\mathrm{mg} / \mathrm{g} \cdot \mathrm{h})$ & $\mathrm{R}^{2}$ \\
\hline $4.8 \pm 0.3$ & 4.162 & 0.187 & 0.8968 & 6.169 & 0.064 & 2.418 & 0.9961 \\
$9.1 \pm 0.4$ & 6.538 & 0.252 & 0.9559 & 9.328 & 0.062 & 5.435 & 0.9953 \\
$19.6 \pm 0.5$ & 12.473 & 0.205 & 0.9071 & 18.349 & 0.025 & 8.264 & 0.9959 \\
\hline
\end{tabular}

with interaction between the adsorbed molecules, and is not restricted to the formation of a monolayer. This model assumes that as the adsorbate concentration increases, the concentration of adsorbate on the adsorbent surface also increases [31]. The parameters and correlation coefficients obtained for the Langmuir and Freundlich isotherms were calculated for $\mathrm{Pb}^{2+}$ adsorption by S. biloba and are presented in Table 4. Our results show that lead adsorption fits well with the Freundlich model, suggesting a heterogeneous distribution of active sites on the plant surface. These results are compatible with the presence of different functional groups responsible for metal adsorption in Salvinia $[3,14,19,28]$.

The Freundlich $\left(K_{F}\right)$ and heterogeneity $(n)$ constants are two parameters associated with the adsorption capacity and the intensity, respectively. If $n$ value is less than one, the adsorption process is unfavourable, and if it is above unity, adsorption is favourable [32,33]. In the present study, the value of $n$ at equilibrium was 2.256 suggesting favourable adsorption (Table 4). This value also suggests the establishment of strong interactions between the metal and the biomass. Using similar experimental set-ups, [3] reported lower $K_{F}(8.31)$ and $n$ (1.57) values for $\mathrm{Pb}^{2+}$ adsorption by $S$. minima from water samples than those obtained in the present work. Hence, our results suggest that $S$. biloba may be a better choice than S. minima for the phytoremediation of waters contaminated with $\mathrm{Pb}^{2+}$.

A successful metal phytoremediation partially depends on the surface characteristics of the plant. Salvinia biomass has a great specific surface area rich in carbohydrates and carboxyl groups, which may explain its high metal removal capacity $[3,14,19,28]$. The content of macromolecules (carbohydrates, protein, lipids), acidic groups (carboxylic groups) and surface area are key factors which determine the binding mechanism between metal and biomass. Recently, [34] obtained the FTIR-ATR spectrum for S. natans biomass before and after the biosorption process of $\mathrm{Pb}^{2+}$ and $\mathrm{Cr}^{3+}$ ions. These authors reported the presence of different functional groups at Salvinia biomass such as carboxyl, phosphate, amide, hydroxyl and others suggesting the involvement of these functional groups (particularly phosphonates groups) in metals adsorption. In this study, the FTIR-ATR spectrum obtained for S. biloba biomass (Fig. 3) is closely related to that reported by [34]. The bands at 3400$3250 \mathrm{~cm}^{-1}$ are assigned to the $\mathrm{OH}$ stretch of polymeric compounds, the band at $2940-2830 \mathrm{~cm}^{-1}$ refer to the asymmetric and symmetric vibration of methylene $\left(\mathrm{CH}_{2}\right)$, respectively. The peak at $1630 \mathrm{~cm}^{-1}$ corresponds to $\mathrm{C}=\mathrm{O}$ of amide. The peak at $1130-1000 \mathrm{~cm}^{-1}$ is the vibration of C-O-C and O-H of polysaccharides. The strong peaks at $1034-1036 \mathrm{~cm}^{-1}$ cor-
Table 4

Equilibrium parameters for $\mathrm{Pb}^{2+}$ adsorption by $S$. biloba according to Freundlich and Langmuir isotherms

\begin{tabular}{llllllll}
\hline \multicolumn{2}{l}{ Langmuir isotherm } & & \multicolumn{4}{l}{ Freundlich isotherm } \\
\cline { 1 - 2 } $\begin{array}{c}q_{\max } \\
(\mathrm{mg} / \mathrm{g})\end{array}$ & $\begin{array}{c}b \\
(\mathrm{~L} / \mathrm{mg})\end{array}$ & $\mathrm{R}^{2}$ & & $\begin{array}{c}K_{F} \\
(\mathrm{mg} / \mathrm{g})(\mathrm{L} / \mathrm{mg})^{1 / \mathrm{n}}\end{array}$ & $n$ & $\mathrm{R}^{2}$ \\
\hline 21.786 & 2.623 & 0.9685 & & 15.020 & 2.256 & 0.9921 \\
\hline
\end{tabular}

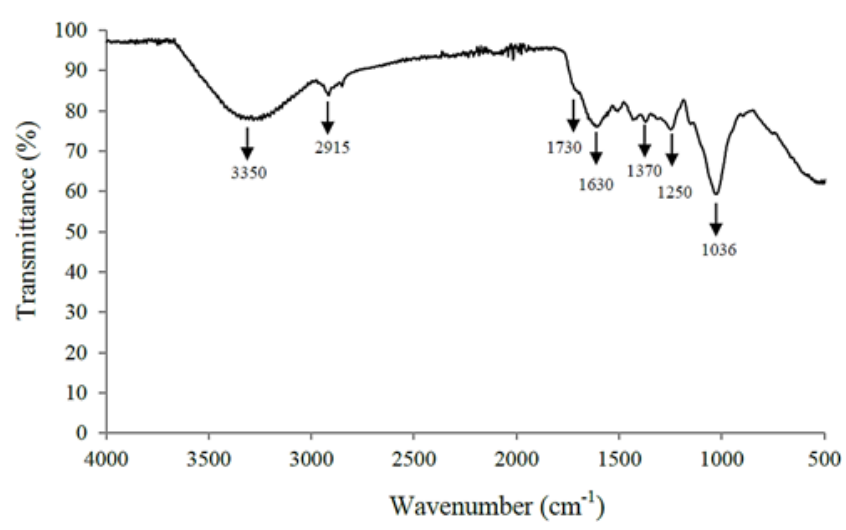

Fig. 3. FTIR-ATR spectrum of S. biloba biomass.

respond to alcohol groups. The $1250 \mathrm{~cm}^{-1}$ peak is the $\mathrm{C}-\mathrm{O}$ stretch of carboxylic acids. The bands $<800 \mathrm{~cm}^{-1}$ are the fingerprint zone which include phosphate and sulphur functional groups [35]. So, it is expected that all macrophytes of Salvinia family share similar biosorption mechanisms.

\subsection{Analysis of compartmentalization}

To understand the fate of lead within the biomass microcosm, a compartmentalization analysis was carried out according to the methodology proposed by [14]. The greatest amount of $\mathrm{Pb}^{2+}$ removed from the water column was adsorbed onto plant roots, regardless of the initial metal concentration and exposure time (Fig. 4), indicating that adsorption on the surface of the plant was the main mechanism observed under the experimental conditions tested. The second most important mechanism for $\mathrm{Pb}^{2+}$ removal was accumulation within the cells. However, metal accumulation was found in a lower proportion. After $24 \mathrm{~h}$, $\mathrm{Pb}^{2+}$ accumulated within plant cells represented near 25\% of the total initial concentration. Moreover, within the range of concentration tested, the $\mathrm{Pb}^{2+}$ intracellular accumulation 


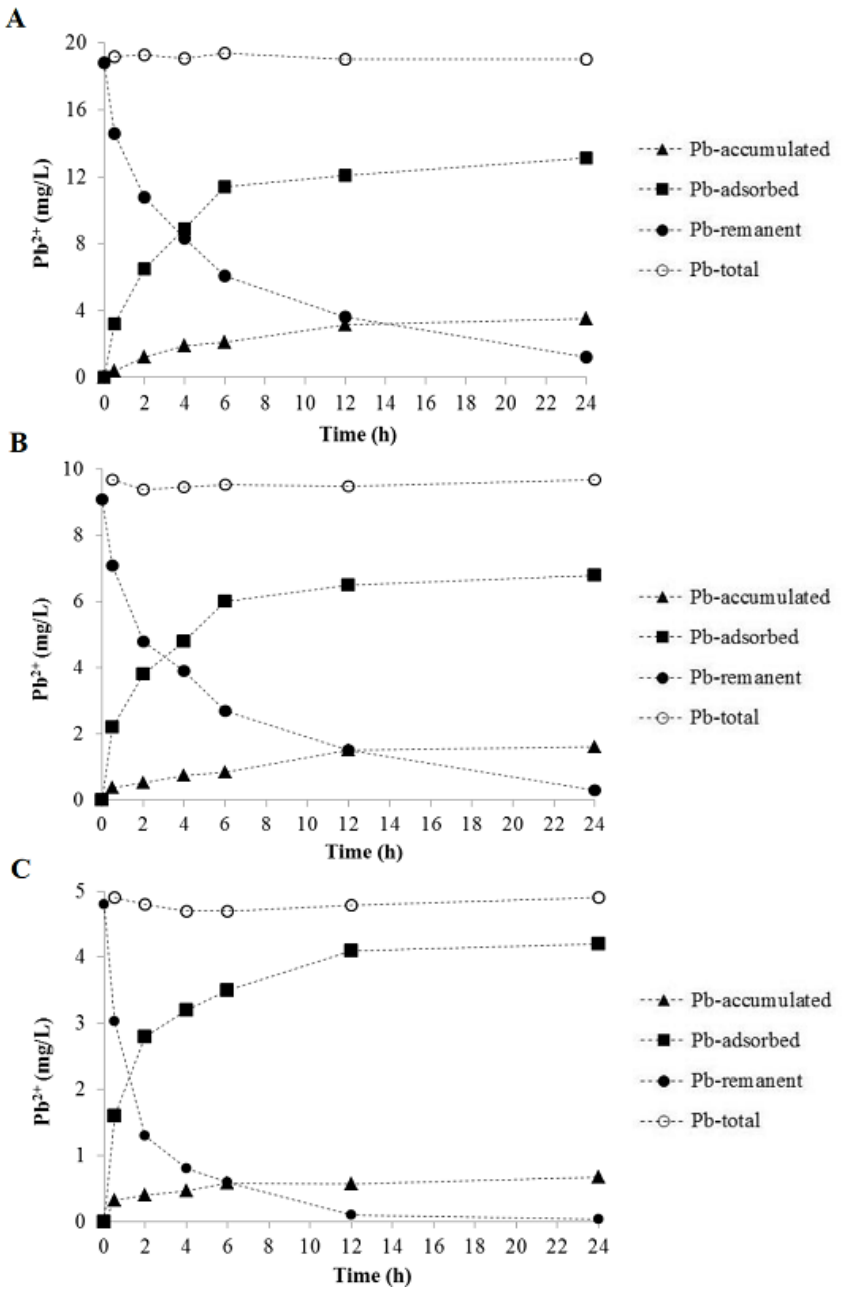

Fig. 4. Compartmentalization analysis in microcosms of batchoperated systems with $S$. biloba using deionized water as an experimental medium at three different initial $\mathrm{Pb}^{2+}$ concentrations: A) $19.6 \pm 0.5 \mathrm{mg} / \mathrm{L}$, B) $9.1 \pm 0.4 \mathrm{mg} / \mathrm{L}$, and C) $4.8 \pm 0.3 \mathrm{mg} / \mathrm{L}$.

rates fitted a Michaelis-Menten model (data not shown) in accordance with previous observations reported by [3].

The percentage of lead remaining in the water column was less than $10 \%$ for each metal concentration evaluated. Noticeably, [20] reported that after 30 days the amount of metal accumulated in plant biomass increased with the concomitant decrease in the adsorbed metal at roots. This observation involves the metal translocation from roots into the aerial part (leaves) suggesting the presence of membrane carrier proteins at plant surface. In this connection, [36] reported that $\mathrm{Pb}^{2+}$ ions induce the production of phytochelatins in S. minima and so these proteins are involved in detoxification processes as part of a metal-tolerance mechanism developed by the plant.

\subsection{Evaluation of $B C F$}

Ambient metal concentration in aquatic media is one of the critical factors that influence metal uptake efficiency in aquatic plants [37]. It has been suggested that BCF can be used as a blueprint of metal uptake efficiency of aquatic macrophytes in phytoremediation trials $[38,39]$. The BCF values for $\mathrm{Pb}^{2+}$ calculated after $24 \mathrm{~h}$ for S. biloba were 1255, 1235 and 1202 for initial $\mathrm{Pb}^{2+}$ concentrations of $4.8 \pm 0.3$ $\mathrm{mg} / \mathrm{L}, 9.1 \pm 0.4 \mathrm{mg} / \mathrm{L}$ and $19.6 \pm 0.5 \mathrm{mg} / \mathrm{L}$, respectively. Interestingly, these values did not significantly change against increasing $\mathrm{Pb}^{2+}$ concentrations in the water sample. In general, high $\mathrm{BCF}$ values denote the accumulative loads of different metals in plant biomass, which can be used as an indicator parameter to select a plant or a treatment set-up for designing a phytoremediation system. Comparatively, the value of $\mathrm{BCF}$ for $\mathrm{Pb}^{2+}$ was higher than the $\mathrm{BCF}$ values reported by several authors for $\mathrm{Cu}^{2+}, \mathrm{Cd}^{2+}$ and $\mathrm{Cr}(\mathrm{III})$, suggesting that $\mathrm{S}$. biloba can remove $\mathrm{Pb}^{2+}$ with high accumulative efficiency $[21,40,41]$. The physiological need for metals in plant and uptake kinetics directly or indirectly affects the accumulative process for certain species of metals. BCF values over 1000 indicate suitability of a plant (i.e. hyper-accumulative plant) for phytoremediation. On the basis of our results, S. biloba can be considered as a hyper-accumulator for $\mathrm{Pb}^{2+}$ under the conditions set at the present study, which suggests that this water fern is appropriate for the removal of heavy metals from wastewaters.

\section{Conclusions}

The aim of the present study was to analyze autochthonous aquatic macrophytes obtained from Paraná river (Argentina) in order to evaluate the metal removal capacity for phytoremediation purposes. Four different aquatic plants were studied but only S. biloba was found to be efficient for growth at non-supplemented ambient conditions. Moreover, S. biloba proved to be highly effective for lead removal from water samples suggesting that this water fern could be used for designing cost-effective plant-based biotechnologies for heavy metal removal from the environment. Additionally, insight into S. biloba $\mathrm{Pb}^{2+}$ removal mechanisms was also discussed using a compartmentalization analysis. Our results demonstrated that surface adsorption was the main mechanism used by this plant to remove the metal in the first $24 \mathrm{~h}$ whereas lead accumulation occurs in a lower proportion. However, large-scale performance and long-term efficiency of $S$. biloba should be further analyzed in order to develop a bioremediation system for industrial scale wastewater management.

\section{Acknowledgements}

The authors wish to thank to the Faculty of Chemistry and Engineering of the Pontifical Catholic University of Argentina (UCA-campus Rosario) and to the National Scientific and Technical Research Council (CONICET) for the funds provided. Mg. Eng. W. Tello Zevallos thank to the National Scholarship and Educational Credit Program (PRONABEC) of the Ministry of Education of the Peru for the financial support. We would like to thank the staff from the English Department (Facultad de Ciencias Bioquímicas y Farmacéuticas, UNR, Argentina) for the language correction of the manuscript. We also want to express our gratitude to Dr. M. Sol Herrero and Lic. C.Daniela Bergara for the technical support. 


\section{References}

[1] H. Ali, E. Khan, M.A. Sajad, Phytoremediation of heavy metals - concepts and applications, Chemosphere, 91 (2013) 869-881.

[2] G. Flora, D. Gupta, A. Tiwari, Toxicity of lead: a review with recent updates, Interdiscip. Toxicol., 5 (2012) 47-58, doi: 10.2478/v10102-012-0009-2.

[3] G. Sánchez-Galván, O. Monroy, J. Gómez, E.J. Olguín, Assessment of the hyperaccumulating lead capacity of Salvinia minima using bioadsorption and intracellular accumulation factors, Water Air Soil Pollut., 194 (2008) 77-90.

[4] K. Kalia, S.J. Flora, Strategies for safe and effective therapeutic measures for chronic arsenic and lead poisoning, J. Occup. Health, 47 (2005) 1-21.

[5] S.H. Abbas, I.M. Ismail, T.M. Mostafa, A.H. Sulaymon, Biosorption of heavy metals: a review, J. Chem. Sci. Technol., 3 (2014) 74-102.

[6] D. Sukumaran, D. Phytoremediation of heavy metals from industrial effluent using constructed wetland technology, Appl. Ecol. Environ. Sci., 1 (2013) 92-97.

[7] M.N.V. Prasad, Phytoremediation of metal-polluted ecosystems: hype for commercialization, Russ. J. Plant Physiol., 50 (2003) 686-700.

[8] P. Sharma, S. Pandey, Status of phytoremediation in world scenario, Int. J. Environ. Biorem. Biodeg., 2 (2014) 178-191.

[9] R. Dixit, E. Wasiullah, D. Malaviya, K. Pandiyan, U.B. Singh, A. Sahu, R. Shukla, B.P. Singh, J.P. Rai, P. Kumar, H. S. and D. Paul, Bioremediation of heavy metals from soil and aquatic environment: an overview of principles and criteria of fundamental processes, Sustainability, 7 (2015) 2189-2212.

[10] P.K. Rai, Heavy metal pollution in aquatic ecosystems and its phytoremediation using wetland plants: an ecosustainable approach, Int. J. Phytoremediat., 10 (2008) 133-160.

[11] P.K. Rai, Heavy metal phytoremediation from aquatic ecosystems with special reference to macrophytes, Crit. Rev. Environ Sci. Technol., 39 (2009) 697-753.

[12] T. Macek, M. Macková, J. Kas, Exploitation of plants for the removal of contaminants in environmental remediation, Biotechnol. Adv., 18 (2000) 23-34.

[13] E.R. De La Sota, Nuevos sinónimos en Salvinia Ség. (Salviniaceae-Pteridophyta), Darwiniana, 33 (1995) 309-313.

[14] E.J. Olguín, G. Sánchez-Galván, T. Pérez-Pérez, A. PérezOrozco, Surface adsorption, intracellular accumulation and compartmentalization of lead in batch-operated lagoons with Salvinia minima as affected by environmental conditions, EDTA and nutrients, J. Ind. Microbiol. Biotechnol., 32 (2005) 577-586.

[15] N.K. Lazaridis, D.D. Asouhidou, Kinetics of sorption removal of chromium (VI) from aqueous solutions by calcined $\mathrm{Mg}-\mathrm{Al}-\mathrm{CO}_{3}$ hydrotalcite, Water Res., 37 (2003) 2875-2882.

[16] Y.S. Ho, G. McKay, Pseudo-second order model for sorption processes, Process Biochem., 34 (1999) 451-465.

[17] Standard methods for the examination of water and wastewater, American Public Health Association, New York, 1998, 1268 p.

[18] A. Zayed, S. Gowthaman, N. Terry, Phytoaccumulation of trace elements by wetland plants: I. Duckweed, J. Environ. Qual., 27 (1998) 715-721.

[19] B. Dhir, Salvinia: An aquatic fern with potential use in phytoremediation, Environ. We Int. J. Sci. Tech., 4 (2009) 23-27.

[20] W. Tello Zevallos, D.B. Loureiro, M.C. Reeves, F. Yujnovsky, L.M. Salvatierra, L.M. Pérez, Biorremediación de aguas contam inadas con metales pesados empleando macrófitas autóctonas de flotación libre. $4^{\text {to }}$ Simposio Argentino de Procesos Biotecnológicos (SAPROBIO 2016), Buenos Aires, Argentina.

[21] M.A. Maine, M. Duarte, N. Suñé, Cadmium uptake by floating macrophytes, Water Res., 35 (2001) 2629-2634.
[22] S. Mukherjee, S. Kumar, Adsorptive uptake of arsenic (V) from water by aquatic fern Salvinia natans, J. Water Supply Res. T., 54 (2005) 47-53.

[23] N. Suñé, G. Sánchez-Galván, S. Caffaratti, M.A. Maine, Cadmium and chromium removal kinetics from solution by two aquatic macrophytes, Environ. Pol., 145 (2007) 467-473.

[24] D. Kratochvil, B. Volesky, Advances in the biosorption of heavy metals, Trends Biotechnol., 16 (2005) 291-300.

[25] R. Chakraborty, S. Karmakar, S. Mukherjee, S. Kumar, Kinetic evaluation of chromium (VI) sorption by water lettuce (Pistia), Water Sci. Technol., 69 (2014) 195-201.

[26] D. Paliulis, Numerical modeling of kinetics of heavy metal sorption from polluted water, J. Environ. Eng. Landsc., 14 (2006) 10-15.

[27] W. Plazinski, J. Dziuba, W. Rudzinski, Modeling of sorption kinetics: the pseudo-second order equation and the sorbate intraparticle diffusivity, Adsorption, 19 (2013) 1055-1064.

[28] I.A.H. Schneider, J. Rubio, Sorption of heavy metal ions by the non-living biomass of freshwater macrophytes, Environ. Sci. Technol., 33 (1999) 2213-2217.

[29] P. Miretzky, A. Saralegui, A.F. Cirelli, Aquatic macrophytes potential for the simultaneous removal of heavy metals (Buenos Aires, Argentina), Chemosphere, 57 (2004) 997-1005.

[30] P. Miretzky, A. Saralegui, A.F. Cirelli, Simultaneous heavy metal removal mechanism by dead macrophytes, Chemosphere, 62 (2006) 247-254.

[31] A. Demirbas, Heavy metal adsorption onto agro-based waste materials: A review, J. Hazard. Mater., 157 (2008) 220-229.

[32] M. Roulia, A.A. Vassiliadis, Sorption characterization of a cationic dye retained by clays and perlite, Microp. Mesop. Mater., 116 (2008) 732-740.

[33] G. Vijayakumar, R. Tamilarasan, M. Dharmendirakumar,Adsorption, kinetic, equilibrium and thermodynamic studies on the removal of basic dye Rhodamine-B from aqueous solution by the use of natural adsorbent perlite, J. Mater. Environ. Sci., 3 (2012) 157-170.

[34] L.K.S. Lima, M.G.C. Silva, M.G.A. Vieira, Study of binary and single biosorption by the floating aquatic macrophytes Salvinia natans, Braz. J. Chem. Eng., 33 (2016) 649-660.

[35] S. Saygideger, O. Gulnaz, E.S. Istifli, N. Yucel, Adsorption of $\mathrm{Cd}(\mathrm{II}), \mathrm{Cu}(\mathrm{II})$ and $\mathrm{Ni}(\mathrm{II})$ ions by Lemna minor L.: Effect of physicochemical environment, J. Hazard. Mater., 126 (2005) 96-104.

[36] N. Estrella, D. Mendoza, R. Moreno, D. González, O. Zapata, A Martínez, J.M. Santamaría, The Pb-hyperaccumulator aquatic fern Salvinia minima Baker, responds to $\mathrm{Pb}^{2+}$ by increasing phytochelatins via changes in SmPCS expression and in phytochelatin synthase activity, Aquatic Toxicol., 91 (2009) 320-328.

[37] R. Verma, S. Suthar, Lead and cadmium removal from water using duckweed-Lemna gibba L.: Impact of $\mathrm{pH}$ and initial metal load, Alexandria Eng. J., 54 (2015) 1297-1304.

[38] A. Göthberg, M. Greger, K. Holm, B.E. Bengtsson, Influence of nutrient levels on uptake and effects of mercury, cadmium, and lead in water spinach, J. Environ. Qual., 33 (2004) 12471255.

[39] F. Duman, Z. Leblebici, A. Aksoy, Bioaccumulation of nickel, copper, and cadmium by Spirodela polyrhiza and Lemna gibba, J. Fresh. Ecol., 24 (2009) 177-179.

[40] M.A. Maine, N. Suñé, S.C. Lagger, Chromium bioaccumulation: comparison of the capacity of two floating aquatic macrophytes, Water Res., 38 (2004) 1494-1501.

[41] M.V. Casares, L.I. de Cabo, R.S. Seoane, A.F. de Iorio, Copper removal efficiency in a surface water and compartmentalization in the floating fern Salvinia minima, Int. J. Environ. Monit. Anal., 2 (2014) 42-47. 